\title{
Identification of a Contractile Function for Renal Medullary Interstitial Cells
}

Alisa K. Hughes, ${ }^{*}$ William H. Barry, ${ }^{\ddagger}$ and Donald E. Kohan *

Divisions of *Nephrology and ${ }^{\ddagger}$ Cardiology, Department of Medicine, Veterans Affairs Medical Center and the University of Utah School of Medicine and the Eccles Program in Human Molecular Biology and Genetics, Salt Lake City, Utah 84132

\begin{abstract}
Renomedullary interstitial cells (RMIC) are unique to the renal medulla. By virtue of their anatomic location and arrangement, RMIC may hinder axial dissipation of the concentration gradient, thereby aiding urinary concentration. A more active role in urinary concentration has been postulated on the basis of speculations about RMIC contractile potential, however, RMIC contraction has not been investigated. To determine if these cells are contractile, cultured rat RMIC were exposed to endothelin-1 (ET-1), a potent vasoconstrictor which binds to RMIC, and examined using video microscopy. ET-1 (as low as 10 pM) caused a slowly developing and dose-dependent reduction in RMIC surface area. ET-1 markedly increased the number and intensity of F-actin microfilament staining. ET-1-induced RMIC contraction was not altered by nifedipine, was partially reduced by nickel, and was completely inhibited by $\mathrm{H7}$, indicating that ET-1 action is mediated by protein kinase $\mathrm{C}$ and is partially dependent upon receptor-operated calcium channels. The ET-1 effect does not involve nitric oxide since $N^{\mathrm{G}}$. monomethyl-L-arginine did not alter ET-1-induced RMIC contraction; in addition, ET-1 had only a minor effect on cGMP levels and no effect on nitrite production. PGE $_{\mathbf{2}}$ acts in an autocrine manner to dampen ET action since indomethacin potentiates, while PGE $_{2}$ inhibits, ET-1-induced RMIC contraction. The contractile response is not unique to ET-1 since vasopressin also reduces RMIC surface area and increases F-actin microfiliment staining. These studies demonstrate that RMIC in culture are contractile. The possibility is raised that contraction of RMIC plays a role in modifying urinary concentration as well as regulation of other renal medullary functions. (J. Clin. Invest. 1995. 96:411-416.) Key words: kidney $\bullet$ medulla $\bullet$ urine $\cdot$ concentration - prostaglandin $\mathbf{E}_{2}$

\section{Introduction}

Renomedullary interstitial cells (RMIC) ${ }^{1}$ are stellate cells that are unique to the renal medulla and are most prevalent towards

Address correspondence to Donald E. Kohan, Division of Nephrology and Hypertension, University of Utah Medical Center, Salt Lake City, UT 84132. Phone:801-585-5219; FAX:801-581-4343.

Received for publication 5 January 1995 and accepted in revised form 21 March 1995.

1. Abbreviations used in this paper: ANF, atrial natriuretic factor; AVP, arginine vasopressin; ET, endothelin; H7, 1-(5-isoquinoline sulfonyl)2-methylpiperazine dihydrochloride; NMMA, $N^{\mathrm{G}}$-monomethyl-L-arginine monoacetate; NO, nitric oxide; RMIC, renomedullary interstitial cells.

The Journal of Clinical Investigation, Inc.

Volume 96, July 1995, 411-416 the papillary tip $(1,2)$. They are perhaps best known for their ability to synthesize large quantities of vasodepressor lipids or lipid precursors, including $\mathrm{PGE}_{2}$ and medullipin I $(3,4)$. Release of these lipids by RMIC has been postulated to play a role in regulating blood pressure and the development of hypertension (5). RMIC may also be involved in regulating urine concentration, however such a role for these cells has not been well studied. RMIC typically bridge the interstitium between medullary blood vessels and thin limbs of Henle's loops, forming a ladder-like arrangement with the long axis of the cells perpendicular to the long axis of the papilla (6). This anatomic arrangement suggests a number of functions that RMIC may play in maintaining urinary concentrating ability. Most apparently, they could provide structural support for the medulla and papilla. In addition, because of their orientation, RMIC are likely to hinder axial diffusion in the medulla (6), thereby limiting dissipation of the solute concentration gradient. In regards to this latter point, it is interesting to note that the kangaroo rat, a desert rodent with the ability to concentrate urine to an unusually high degree, has the greatest abundance of papillary RMIC known (7). A third possible function for RMIC has been postulated: contraction. These cells have cytoplasmic myoid fibrils (8) and, as mentioned above, are anchored to adjacent blood vessels and Henle's loops. In 1956, Sternberg and coworkers noted that "should these cells (RMIC) prove to have a contractile function, they might play a role in the regulation of urinary volume,' (7). In 1990, Fontoura et al. described atrial natriuretic factor (ANF) receptors on RMIC and noted that the contractile state of RMIC may influence flow, pressure, or passive permeability characteristics of the vasa recta or Henle's loops (9). To date, however, a contractile ability of RMIC has not been reported. The purpose of the current study was, therefore, to determine if RMIC were contractile.

A number of vasoactive mediators have been demonstrated to bind to, and activate signal transduction systems in, RMIC. These include atrial natriuretic factor (9), nitric oxide (10), angiotensin II $(4,11)$, bradykinin $(4)$, vasopressin $(4,12)$, and endothelin-1 (ET-1) (13). Because of ongoing research interest by this laboratory in the production and actions of ET-1 in the renal medulla (14-16), we chose to examine the effect of this peptide on RMIC contraction. ET-1 is a 21-amino acid peptide that is the most potent vasoconstrictor known (17). It binds to high affinity receptors on RMIC and elicits an increase in cytosolic- free $\mathrm{Ca}^{2+}$ concentration that is dependent in part upon increases in inositol trisphosphate levels and receptor-operated $\mathrm{Ca}^{2+}$ channels (13). We report that ET-1 causes a long-lasting and potent contraction of cultured rat RMIC. In addition, the mechanism of ET-1-induced RMIC contraction is explored. Finally, the effect of arginine vasopressin (AVP) on RMIC contraction is examined to determine if the response is unique to ET-1.

\section{Methods}

Materials. RPMI-1640 and bovine calf serum were obtained from Hyclone Laboratories, Logan, UT; ET-1 was from Penninsula Labora- 
tories, Inc., Belmont, CA; human insulin (Humulin) from Eli Lilly, Indianapolis, IN; $N^{\mathrm{G}}$-monomethyl-L-arginine monoacetate (NMMA) from Chem-Biochem Research, Salt Lake City, UT; rhodamine-phalloidin from Molecular Probes Inc., Grand Junction, OR; and Bradford reagent from Bio-Rad, Richmond, CA. Cover slips and tissue culture plates were obtained from Fisher Scientific Co., Santa Clara, CA. All other reagents were from Sigma Chemical Co., St. Louis, MO unless specified otherwise.

Tissue culture. Renomedullary interstitial cells from Sprague-Dawley rats were a generous gift of Drs. Edward Nord (State University of New York, Stony Brook, NY) and Thomas Maack (Cornell University Medical College, New York, NY). These cells have been extensively characterized and previously described in detail (9). Cells were grown in RPMI-1640 containing $20 \%$ bovine calf serum and $60 \mathrm{U} / \mathrm{ml}$ insulin on 25-mm circular glass cover slips or 24-well plastic plates in a 5\% $\mathrm{CO}_{2}$ environment at $37^{\circ} \mathrm{C}$. Experiments were performed at $30-50 \%$ confluence on passages 22-27 (18-40 h after initial plating).

Measurements of changes in cell surface area. On the day of study, cells were washed twice with Krebs buffer $(145 \mathrm{mM} \mathrm{NaCl}, 10 \mathrm{mM}$ Hepes, $5 \mathrm{mM}$ glucose, $5 \mathrm{mM} \mathrm{KCl}, 1 \mathrm{mM} \mathrm{Na}_{2} \mathrm{HPO}_{4}, 2.5 \mathrm{mM} \mathrm{CaCl}_{2}$, $1.8 \mathrm{mM} \mathrm{MgSO}_{4}, \mathrm{pH} \mathrm{7.3)}$ and incubated in $\mathrm{KRB}$ at $37^{\circ} \mathrm{C}$ for $30 \mathrm{~min}$ (preincubation solution). The coverslips were then placed in a $37^{\circ} \mathrm{C}$ incubation chamber with a clear glass bottom (18) containing $5 \mathrm{ml}$ KRB (incubation solution) on the stage of an inverted microscope (Diaphot, Nikon Inc., Tokyo, Japan). The cell image was obtained by 700 $\mathrm{nm}$ illumination and collected by a phase contrast $40 \times$ objective lens (Nikon Ph3 40 DL; Nikon Inc.) and monitored with a video camera (model 540; Pulnex, Sunnyvale, CA) attached to the video port of the microscope. Live images were recorded on a video cassette recorder (HRD 750U; JVC, Salt Lake City, UT) and played back for analysis. Cell surface area changes were measured by tracing the video imaged cell perimeter onto transparent film (PP2200; 3M Co., St. Paul, MN). The tracings were cut out and weighed. All measurements of surface area involved determination of the initial cell area at the time of placing the cell into the incubation chamber (termed "time 0") followed by measurements of the same cell area over the next $30-60 \mathrm{~min}$. All results were calculated by comparing the surface area after various incubation times to the area at time 0 in the same cell.

Experimental protocols for measuring changes in cell surface area. For control measurements, RMIC were preincubated in KRB for 30 min, then placed in KRB alone in the incubation chamber for 30-60 $\min$. Changes in surface area were assessed over the duration of the incubation. Varying concentrations of ET-1 or $10 \mathrm{nM}$ AVP were added immediately after the coverslips were placed in the incubation chamber and baseline cell surface area recorded. Cell surface area was then recorded for 30-60 min in the presence of ET-1 or AVP. For studies on the effects of nifedipine, nickel, NMMA, indomethacin, and 1-(5isoquinoline sulfonyl)-2-methylpiperazine dihydrochloride (H7) on ET-1-induced contractions two protocols were followed. In the first, the effects of these reagents alone on cell surface area was determined in a manner identical to that for ET-1 above. In the second, the effects of these reagents on ET-1 actions was assessed by preincubating the cells for $30 \mathrm{~min}$ with the above reagents. The cells were then placed in the incubation chamber, ET-1 added in the continued presence of the various compounds, and changes in surface area assessed for $\mathbf{3 0 ~ m i n ~ a s ~}$ described above. Finally, for studies with $\mathrm{PGE}_{2}, \mathrm{PGE}_{2}$ and ET-1 were added at the same time to cells that had been preincubated in indomethacin.

Staining of F-actin microfilaments. RMIC were stained using previously described methodology (19). Briefly, cells were incubated in KRB alone or containing $10 \mathrm{nM}$ ET-1 or $10 \mathrm{nM}$ AVP for $30 \mathrm{~min}$ at $37^{\circ} \mathrm{C}$. Coverslips were then rinsed in PBS, fixed with $3.7 \%$ formaldehyde in PBS for 10 min at $23^{\circ} \mathrm{C}$, rinsed, permeabilized with $0.2 \%$ Triton X100 in PBS for $1 \mathrm{~min}$ at $23^{\circ} \mathrm{C}$, and rinsed again. Cells were then incubated with $5.0 \mathrm{U} / \mathrm{ml}$ rhodamine-phalloidin in PBS for $30 \mathrm{~min}$ in the dark on a rotary shaker, rinsed, and mounted using 1:1 PBS/glycerol, and photographed using a microscope (Carl Zeiss, Inc., Thornwood, NY) equipped with a mercury lamp, epifluorescence illumination, and a camera (Polaroid Corp., Cambridge, MA). All photomicrographs were obtained under identical conditions.

Determination of cyclic nucleotide accumulation. RMIC in 24-well plates were preincubated with $0.1 \mathrm{mM}$ 3-isobutyl-1-methylxanthine for $30 \mathrm{~min}$ in KRB followed by addition of varying concentrations of ET1 for $5-10 \mathrm{~min}$ at $37^{\circ} \mathrm{C}$. The media was then removed and the cells treated with $100 \%$ ethanol overnight. The ethanol was subsequently evaporated, the samples resuspended in assay buffer and cGMP, and cAMP determined using commercially available radioimmunoassay kits (Amersham Corp., Arlington Heights, IL). The remaining cell protein was solubilized in $0.1 \mathrm{~N} \mathrm{NaOH}$, an aliquot mixed with Bradford reagent, and protein concentration determined by measuring absorbance at 590 $\mathrm{nm}$ (20). All results were expressed as femtomoles cyclic nucleotide per microgram total cell protein. As a positive control for cGMP, RMIC were exposed to $10 \mathrm{nM}$ ANF for $10 \mathrm{~min}$.

Determination of nitrite levels. RMIC in 24-well plates were exposed to $0.1-100 \mathrm{nM} \mathrm{ET}-1$ in $\mathrm{KRB}$ at $37^{\circ} \mathrm{C}$ for 5-30 min. After incubation, duplicate $50-\mu \mathrm{l}$ aliquots of the supernatants were removed and immediately tested for nitrite $\left(\mathrm{NO}_{2}^{-}\right)$levels (stable breakdown product of nitric oxide) as previously described (21). To each aliquot, $100 \mu \mathrm{l}$ of Greiss reagent ( $1 \%$ sulfanilamide in $30 \%$ acetic acid and $0.1 \% \mathrm{~N}$ (1-naphthyl)ethylenediamine dihydrochloride in $60 \%$ acetic acid in a 1:1 mixture) was added and mixed for one min. Absorbance at 550 $\mathrm{nm}$ was immediately measured in a microplate reader (Thermomax; Molecular Devices Corp., Menlo Park, CA). $\mathrm{NO}_{2}^{-}$levels were determined by comparing sample values with a standard curve established with known quantities of sodium nitrite. The cells were solubilized with $0.1 \mathrm{~N} \mathrm{NaOH}$ and total protein determined as described above.

Statistics. All results are compared by ANOVA. $P<0.05$ was deemed significant as determined by the Scheffe F-test. All data are expressed as mean \pm SEM.

\section{Results}

RMIC contraction. Incubation of RMIC in KRB alone for up to $60 \mathrm{~min}$ had no significant effect on cell surface area. ET-1 (10 $\mathrm{nM}$ ) caused a slowly developing reduction in surface area that was maximal ( $75.3 \pm 1.9 \%$ of original cell surface area) 30 min after addition of the peptide (Fig. $1 B$ ). The response to ET-1 was dose-dependent with a significant, albeit small, contraction occurring at 10 pM ET-1 (Fig. $1 \mathrm{~A}$ ). Cells were stained for F-actin filaments (with rhodamine-phalloidin) after a 30-min incubation in KRB alone or containing $10 \mathrm{nM}$ ET-1. As is apparent from Fig. 3, ET-1 caused a marked increase in the number and the intensity of F-actin filaments in RMIC, providing further support for ET-1-stimulated contractile activity by RMIC.

AVP ( $10 \mathrm{nM}$ ) also contracted RMIC (Fig. 2). The response to AVP was maximal by $15 \mathrm{~min}$ and persisted for at least $1 \mathrm{~h}$. This was faster than the contraction observed with ET-1; the reasons for the different response times is uncertain, but could reflect differences in ligand stimulation of factors modifying RMIC contraction such as $\mathrm{PGE}_{2}$ (see below). Similar to ET-1, AVP caused a marked increase in the number and intensity of F-actin microfilaments (Fig. 3).

Mechanism of ET-1-induced RMIC contraction. To explore the mechanism(s) of ET-1-stimulated RMIC contraction, the effect of a variety of agents on the ET-1 response was examined. As shown in Fig. 4, nifedipine, an inhibitor of voltage-sensitive calcium channels, did not significantly alter ET-1-induced contraction. In contrast, nickel, an inorganic blocker of calcium channels, reduced, but did not completely inhibit, the contractile response to ET-1. Neither nickel nor nifedipine, when given alone, had an effect on RMIC surface area. H7, a protein kinase 

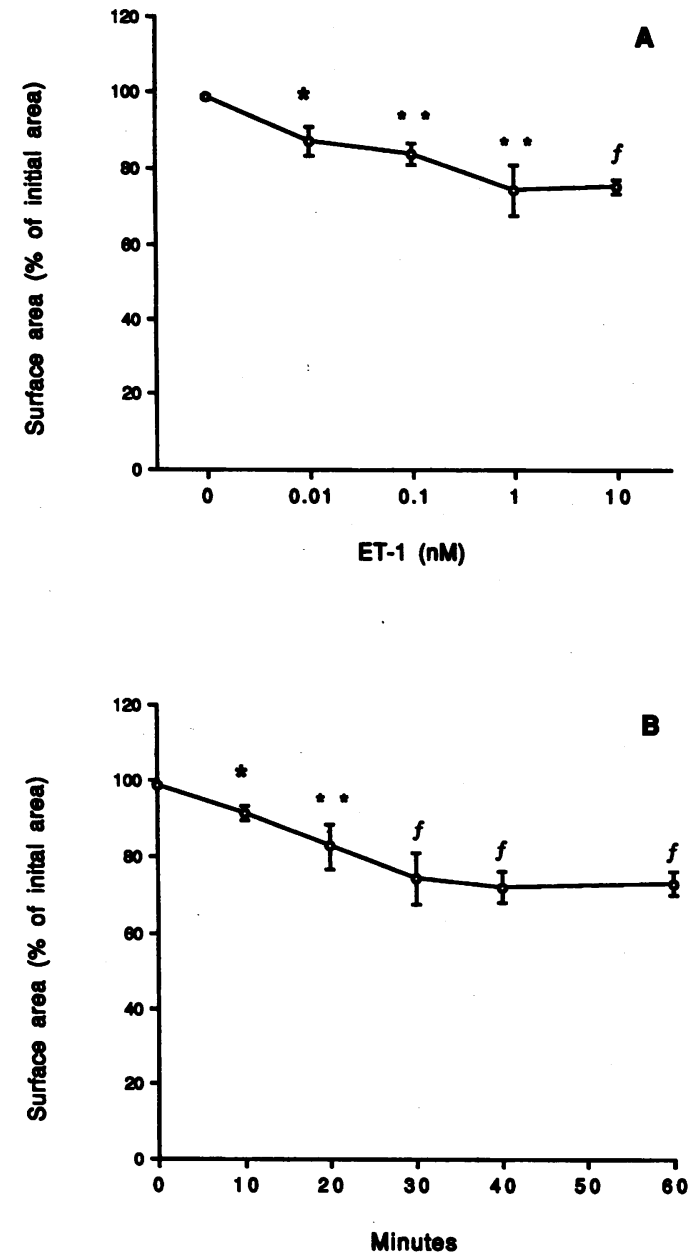

Figure 1. Effect of ET-1 on surface area of rat medullary interstitial cells. $(A)$ Cell area was determined immediately before and $30 \mathrm{~min}$ after addition of 0.01-10 nM ET-1. (B) Cell area was determined immediately before and then $10-60 \mathrm{~min}$ after addition of $10 \mathrm{nM}$ ET1. $n=3-4$ each data point. ${ }^{*} P<0.01 ; * * P<0.005 ;{ }^{f} P<0.001$; all vs control and ${ }^{\mathrm{f}} P<0.005$ vs $0.01 \mathrm{nM}$ ET-1.

C inhibitor, had no effect on unstimulated RMIC surface area, but completely blocked the contractile response to ET-1. Hence, ET-1 stimulated RMIC contraction is dependent in part on voltage-insensitive extracellular calcium entry and is mediated through activation of protein kinase $\mathbf{C}$.

ET-1 stimulates RMIC production of $\operatorname{PGE}_{2}(13,22)$, an eicosanoid which can inhibit the vasoconstrictive effect of ET1 (23). To determine if cyclooxygenase products modify the contractile response to ET-1 in RMIC, cells were treated with indomethacin followed by addition of ET-1 (Fig. 5). Indomethacin alone cause a slight, but significant, increase in RMIC surface area, suggesting that basal cyclooxygenase products may tonically contract these cells. In contrast, indomethacin potentiated the contractile effect of ET-1, suggesting that ET1 stimulation of a cyclooxygenase product decreases the contractile response to the peptide. The effect of $\mathrm{PGE}_{2}$ on the ET1 -induced contraction in the presence of indomethacin was examined since this is the major eicosanoid produced by RMIC. As shown in Fig. 5, $\mathrm{PGE}_{2}$ markedly reduced the contractile response to ET-1, supporting an inhibitory role for the prostanoid.

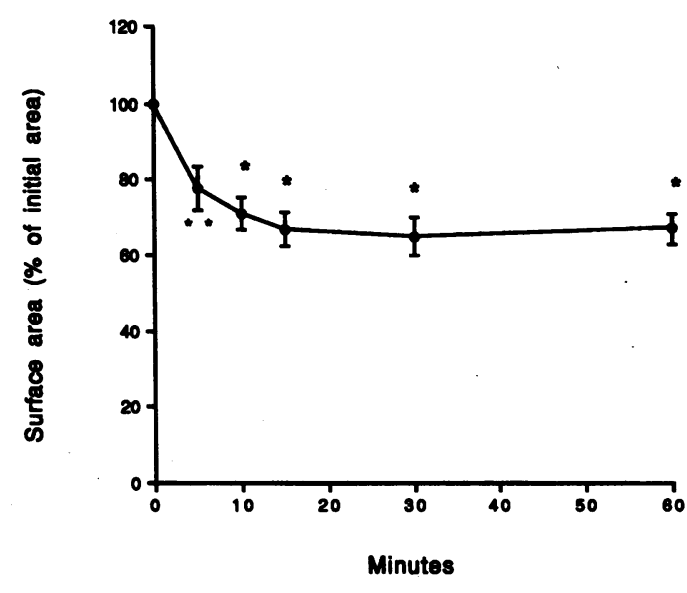

Figure 2. Effect of vasopressin on surface area of rat medullary interstitial cells. Cell area was determined immediately before and then 10$60 \mathrm{~min}$ after addition of $10 \mathrm{nM}$ AVP. $n=7$ each data point. ${ }^{* *} P$ $<0.005$; $* P<0.001$; both vs control.

Nitric oxide (NO) is a well known antagonist of ET-1, inhibiting both ET-1 production (24) and smooth muscle contraction (25). To examine whether NO could be modifying the ET-1 response, RMIC were preincubated with NMMA, an antagonist of NO action. The dose of NMMA used has been previously shown to completely block endogenous NO production by a number of cell types (21). NMMA had no effect on basal RMIC surface area nor did it alter ET-1-induced contraction (Fig. 4), suggesting that NO is not involved in mediating the ET-1 response. Nitrite levels were examined in supernatants of cells incubated with media alone or containing $10 \mathrm{nM}$ ET-1 for up to $30 \mathrm{~min}$, however no nitrite was detected under any conditions. This assay is relatively insensitive since the Greiss reagent detects only microgram quantities of nitrite and could, therefore, have missed less dramatic alterations in endogenous NO production. To further examine an alteration in endogenous NO levels, the effect of ET-1 on cGMP (the mediator of NO actions) accumulation in RMIC was also quantitated. ET-1 did cause a very modest reduction in cGMP levels, but only at relatively high concentrations $(10-100 \mathrm{nM})$ of the peptide (Fig. $6 B$ ). The cGMP system was clearly responsive in these cells as ANF markedly increased cGMP levels. These data suggest, that a small reduction in NO might play a relatively minor role in mediating ET-1-induced RMIC contraction, but is unlikely to be of physiologic significance.

Since alterations in CAMP accumulation have been implicated in cell contraction, the effect of ET- 1 on RMIC cAMP levels was examined. ET-1, at doses which clearly elicited contraction, had no effect on RMIC cAMP accumulation (Fig. 6 $A$ ), indicating that this is not the mechanism by which ET-1induced RMIC contraction occurs.

\section{Discussion}

The current study demonstrates that RMIC are contractile cells. ET-1 and AVP cause a long-lasting reduction in RMIC surface area that is associated with marked increases in the number and intensity of F-actin microfilament staining. The finding that cultured RMIC are contractile suggests that this is an important physiologic property of RMIC in vivo, particularly since cells 

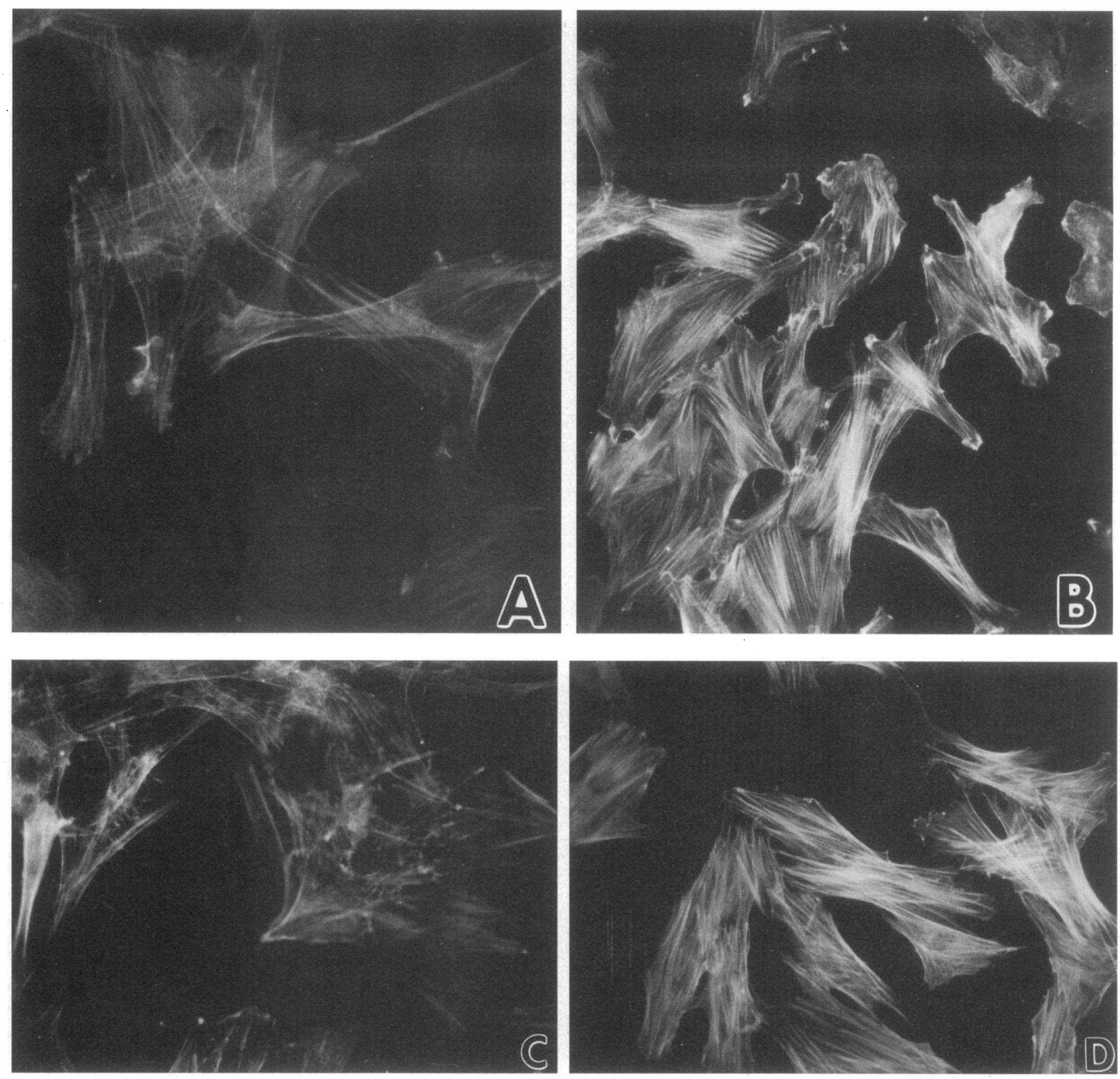

Figure 3. Photomicrographs of rat medullary interstitial cells exposed to media alone $(A)$ and $(C)$, containing $10 \mathrm{nM} \mathrm{ET-1}(B)$, or $10 \mathrm{nM}$ AVP $(D)$ for $30 \mathrm{~min}$. Cells were stained with rhodamine-phalloidin and photographed under fluorescent microscopy using identical exposure conditions. Both photomicrographs are $\times 250$. A representative of five experiments is shown for ET-1 and three experiments for AVP.

in culture tend to lose their contractility. Although it is not possible to draw conclusions about the physiologic relevance of RMIC contraction from the current study, one must consider how the contractile state of these cells could potentially impact on medullary function. RMIC are intimately associated with loops of Henle and blood vessels and, to a lesser extent, with medullary collecting ducts (2). Consequently, RMIC form a bridge predominantly between Henle's loops and blood vessels that are oriented with the long axis of the RMIC perpendicular to the long axis of the papilla (6). This results in a ladder-like structure in which RMIC could limit axial diffusion (6). How then could RMIC contraction modify renal medullary function? First, RMIC contraction may reduce medullary interstitial volume by pulling Henle's loops, blood vessels, and to a lesser extent collecting ducts, closer to one another. This would result in less distance for water and solutes to diffuse, facilitating exchange between the tubules and the blood. Whether this mechanism could be physiologically important is, however, uncertain. Wexler and colleagues have proposed a model to explain medullary urine concentration that assumes a significant physical separation between the collecting duct and Henle's limbs (26). In contrast, anatomical studies have demonstrated a relatively small distance between collecting ducts and Henle's limbs (27), raising doubts as to the role of distance between these tubule segments in modulating urine concentration. This issue remains unresolved, however, since RMIC contraction during the process of tissue fixation could alter medullary geometry. Further, the architecture of the renal medulla is notoriously difficult to preserve during fixation due to the high tonicity (2). A second possibility is that a reduction in papillary volume 


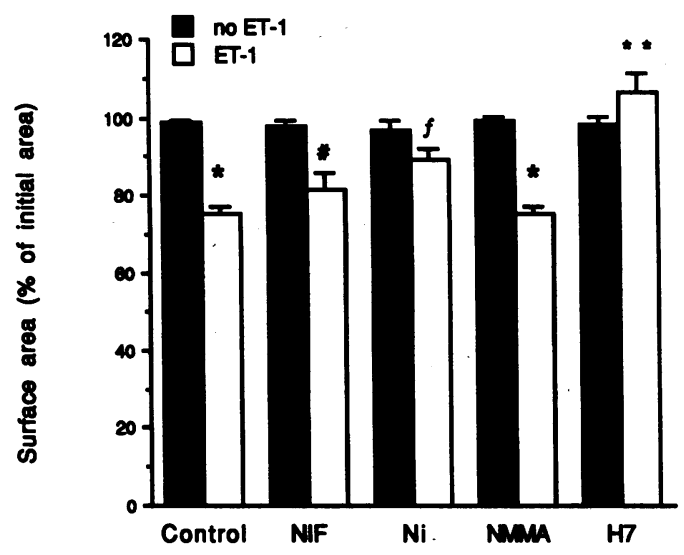

Figure 4. Effect of $10 \mu \mathrm{M}$ nifedipine (NIF), $1 \mathrm{mM} \mathrm{Ni}, 0.5 \mathrm{mM}$ NMMA, and $10 \mu \mathrm{M}$ H7 on $10 \mathrm{nM}$ ET-1-induced contraction by rat medullary interstitial cells. In studies without ET-1, cell area was determined immediately before and $30 \mathrm{~min}$ after addition of the above reagents. In studies with ET-1, cells were preincubated with the above reagents for $30 \mathrm{~min}$ followed by addition of ET-1 for $30 \mathrm{~min}$ in the presence of the various reagents. Cell area was determined immediately before and 30 min after addition of ET-1. $n=3-5$ each data point. ${ }^{*} P<0.001$ vs control and vs same condition in the absence of ET-1; \#P<0.005 vs control and vs NIF alone; ${ }^{f} P<0.005$ vs control or ET- 1 alone and $P<0.025$ vs Ni alone; $* * P<0.001$ vs ET- 1 alone.

caused by RMIC contraction could reduce the energy required to maintain the high solute concentrations, particularly towards the papillary tip. Put another way, if papillary volume is less, there is less solute required to maintain a hypertonic environment and less energy needed to drive the inner medullary concentrating mechanism. Viewed in the above context, one would predict that RMIC contraction would, therefore, favor urine concentration and medullary water reabsorption. Other effects of RMIC contraction must also be considered. Since a single RMIC can encircle up to $30 \%$ or more of the basement membrane of a given cross-section of a loop of Henle or vasa recta $(1,2)$, it is possible that, as previously speculated by Fontoura and coworkers (9), RMIC contraction could alter tubule fluid or blood flow, permeability characteristics of the vasa recta or thin limbs, and even interstitial, tubule, or vascular pressures. The challenge will be to design in vivo studies in which the

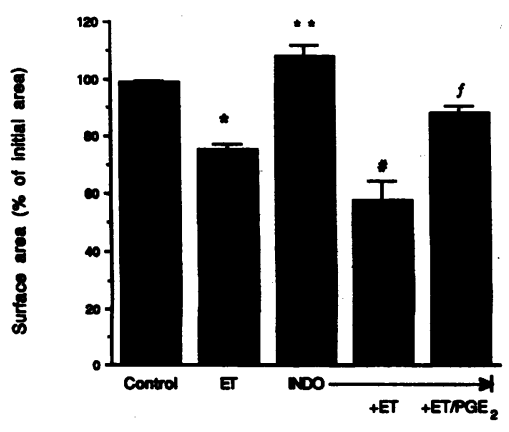

Figure 5. Effect of 10 $\mu \mathrm{M}$ indomethacin (INDO) and $1 \mu \mathrm{M} \mathrm{PGE}_{2}$ on $10 \mathrm{nM}$ ET-1-induced contraction by rat medullary interstitial cells. For INDO alone studies, cell area was determined immediately before and 30 min after addition of INDO. For ET and ET $+\mathrm{PGE}_{2}$ studies, cells were preincubated with INDO for $30 \mathrm{~min}$, followed by addition of ET-1 and/or $\mathrm{PGE}_{2}$ for 30 $\mathrm{min}$. Cell area was determined in these latter studies immediately before and 30 min after addition of ET-1 and/or PGE $2 . n=3-6$ each data point. ${ }^{*} P<0.001$ vs control; ${ }^{* *} P<0.025$ vs control; \# $P<0.001$ vs INDO alone or vs control and $P<0.01$ vs ET-1 alone; ${ }^{\mathrm{f}} P<$ 0.005 vs control, ET-1 alone, and INDO + ET-1.
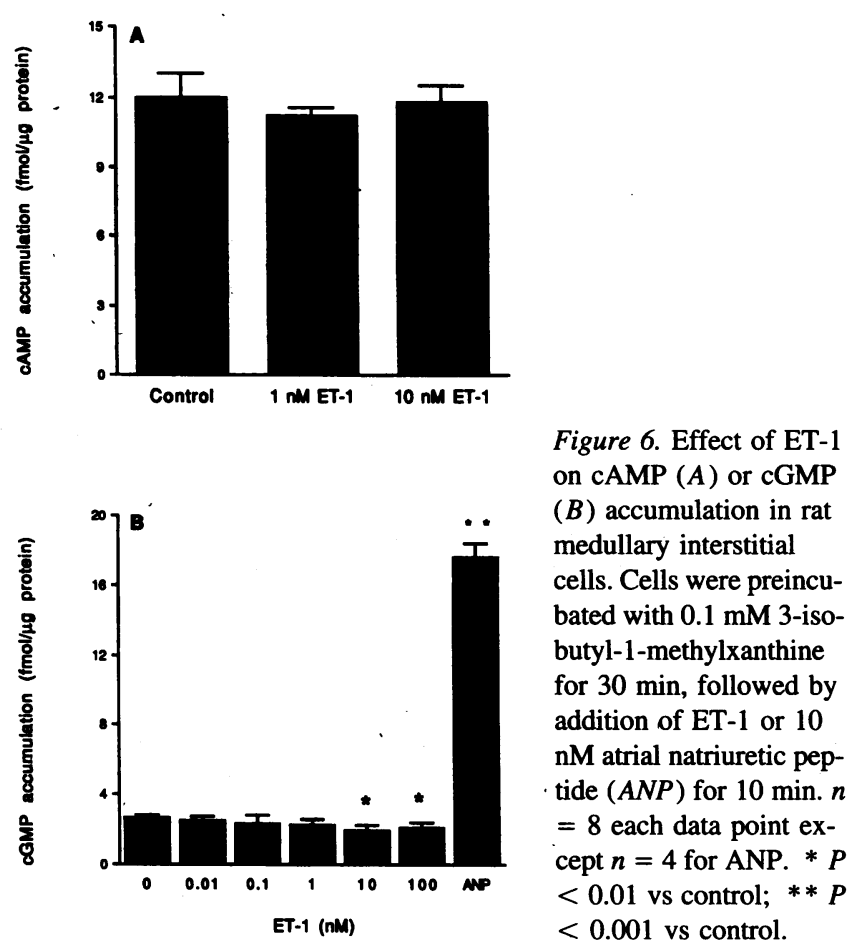

role of RMIC contraction can be tested, however, the current finding that RMIC do indeed contract should provide impetus to the development of relevant techniques.

ET-1 has been demonstrated to bind to RMIC and elicit increases in the concentration of cytosolic-free $\mathrm{Ca}^{2+}$, inositol trisphosphate, and $\mathrm{PGE}_{2}(13,22,28)$. In the current study ET1 was shown to contract RMIC at a concentration as low as 10 $\mathrm{pM}$ and half-maximal contraction at $\sim 100 \mathrm{pM}$. This concentration range for ET-1 action is somewhat lower than that described by Wilkes and coworkers for the initial rise in cytosolic $\mathrm{Ca}^{2+}$ concentration and inositol trisphosphate levels in RMIC (0.5 and $1 \mathrm{nM}$ ET-1, respectively) (13). This group did note, however, that a second sustained rise in cytosolic-free $\mathrm{Ca}^{2+}$ concentration in RMIC was associated with activation of receptoroperated calcium channels and occurred at ET-1 concentrations as low as $1 \mathrm{fm}$. Our finding that nickel, but not nifedipine, inhibits ET-1-induced contraction lends further support to the notion that ET-1 activates dihydropyridine-insensitive, receptoroperated calcium channels in RMIC.

The current study explored several potential mechanisms for ET-1-induced RMIC contraction. ET-1-induced RMIC contraction is dependent upon activation of protein kinase $\mathrm{C}$ since $\mathrm{H} 7$ completely blocks the ET-1 effect. This finding is in agreement with previous data showing that protein kinase $\mathrm{C}$ is an important mediator of at least some aspects of ET-1-induced signal transduction in RMIC (activation of phospholipase D) (28). ET-1 did not alter cAMP levels and only modestly reduced cGMP levels at concentrations of ET-1 that were well above those required to elicit RMIC contraction. Nitric oxide does not appear to mediate the ET-1 response in these cells since NMMA had no effect on RMIC contraction after simulation with ET-1. Perhaps of greatest interest was the finding that indomethacin potentiates ET-1 action, while addition of $\mathrm{PGE}_{2}$ reduces ET-1-elicited RMIC contraction. Taken together with previous studies showing that ET-1 stimulates $\mathrm{PGE}_{2}$ production 
by $\operatorname{RMIC}(13,22)$, these data indicate that $\mathrm{PGE}_{2}$ is a negative modulator of ET-1-stimulated RMIC contraction.

That ET-1 regulates RMIC contraction suggests an interesting and complex system of ET-1 action in the inner medulla. ET-1 is not produced by RMIC (13); rather, it derives from adjacent inner medullary collecting duct (IMCD) (14) and possibly endothelial cells (29). In the IMCD, ET-1 inhibits vasopressin-stimulated water $(30,31)$, and possibly sodium (32), reabsorption. In contrast, we speculate that ET-1, by contracting RMIC, would enhance water reabsorption. RMIC express only $\mathrm{ET}_{\mathrm{A}}$ receptors (13), while ET-1 exerts its effects on IMCD cells through activation of $\mathrm{ET}_{\mathrm{B}}$ receptors (33). Hence, the net effect of ET-1 action in the inner medulla may depend upon the relative degree of activation of the two endothelin receptor subtypes. It should also be noted that these considerations do not take into account ET-1 actions on vasa recta and medullary blood flow.

AVP also contracts RMIC in culture. This demonstrates that RMIC contraction is not unique to ET-1. In addition, it raises the interesting possibility that RMIC contraction might contribute to AVP-mediated increases in urine concentration. Detailed studies on the mechanism of AVP-stimulated RMIC contraction of ET-1 are clearly needed.

In summary, the current study demonstrates that RMIC are contractile cells. ET-1 elicits RMIC contraction through activation of protein kinase $\mathrm{C}$ and receptor-operated calcium channels. AVP also contracts RMIC; the mechanism of this effect requires further investigation. In addition, it will be of great interest to determine the effect of other agents that bind to RMIC, including angiotensin II and ANF, on RMIC contraction. Further, a role for $\mathrm{PGE}_{2}$ in modifying the effects of these agents on RMIC contraction merits examination. Finally, studies are needed which are designed to investigate the role of RMIC contraction in regulating renal medullary function.

\section{Acknowledgments}

The authors thank Dr. Rex Jamison for his helpful comments.

This work was supported in part by Merit Review and Career Development Awards from the Department of Veterans Affairs and by National Institutes of Health grant R29 DK44440 (all to D. E. Kohan).

\section{References}

1. Osvaldo, L., and H. Latta. 1966. Interstitial cells of the renal medulla. $J$. Ultrastruc. Res. 15:589-613.

2. Bohman, S.-O. 1974. The ultrastructure of the rat renal medulla as observed after improved fixation methods. J. Ultrastruc. Res. 47:329-360.

3. Muirhead, E. E. 1991. The medullipin system of blood pressure control Am. J. Hypertens. 4:556S-568S.

4. Zusman, R. M., and H. R. Keiser. 1977. Prostaglandin biosynthesis by rabbit renomedullary interstitial cells in tissue culture. J. Clin. Invest. 60:215223.

5. Muirhead, E. E. 1990. Discovery of the renomedullary system of blood pressure control and its hormones. Hypertension (Dallas). 15:114-116.

6. Lemley, K. V., and W. Kriz. 1991. Anatomy of the renal interstitium. Kidney Int. 39:370-381.

7. Sternberg, W. H., E. Farber, and C. E. Dunlap. 1956. Histochemical localization of specific oxidative enzymes: II. Localization of diphosphopyridine nucleotide and triphosphopyridine nucleotide diaphorases and the succindehydrogenase system in the kidney. J. Histochem. Cytochem. 4:266-283.

8. Harper, J. T., H. Puchttler, S. N. Meloon, and M. S. Terrry. 1970. Lightmicroscopic demonstration of myoid fibrils in renal epithelial, mesangial and interstitial cells. J. Microsc. (Oxf.). 91:71-85.

9. Fontoura, B. M. A., D. R. Nussenzvieg, K. M. Pelton, and T. Maack. 1990.
Atrial natriuretic factor receptors in cultured renomedullary interstitial cells. Am. J. Physiol. 258:C692-C699.

10. Ujiie, K., L. Hogarth, R. Danziger, J. G. Drewett, P. S. T. Yuen, I.-H. Pang, and R. A. Star. 1994. Homologous and heterologous desensitization of a guanylyl cyclase-linked nitric oxicic receptor in cultured rat medullary interstitial cells. J. Pharmacol. Exp. Ther. 270:761-767.

11. Zhuo, J., D. Alcorn, J. McCausland, and F. A. O. Mendelsohn. 1994. Localization and regulation of angiotensin II receptors in renomedullary interstitial cells. Kidney Int. 46:1483-1485.

12. Beck, T. R., A. Hassid, and M. J. Dunn. 1980. The effect of arginine vasopressin and its analogs on the synthesis of prostaglandin $E_{2}$ by rat renal medullary interstitial cells in culture, J. Pharmacol. Exp. Ther. 215:15-19.

13. Wilkes, B. M., A. S. Ruston, P. Mento, E. Giraldi, D. Hart, M. V. Molen, R. Barnett, and E. P. Nord. 1991. Characterization of endothelin 1 receptor and signal transduction mechanisms in rat medullary interstitial cells. Am. J. Physiol. 260:F579-F589.

14. Kohan, D. E. 1991. Endothelin synthesis by rabbit renal tubule cells. Am. J. Physiol. 261:F221-F226.

15. Kohan, D. E., and E. Padilla. 1993. Osmolar regulation of endothelin-1 production by rat inner medullary collecting duct. J. Clin. Invest. 91:1235-1240.

16. Kohan, D. E., and A. K. Hughes. 1993. Autocrine role of endothelin in rat IMCD: inhibition of AVP-induced cAMP accumulation. Am. J. Physiol. 265:F129-F129.

17. Yanagisawa, M., H. Kurihara, S. Kimura, Y. Tomobe, M. Kobayashi, Y. Mitsui, Y. Yazaki, K. Goto, and T. Masaki. 1988. A novel potent vasoconstrictor peptide produced by vascular endothelial cells. Nature (Lond.). 332:411-415.

18. Kohmoto, O., H. Ikenouchi, Y. Hirata, S.-I. Momomura, T. Serizawa, and W. H. Barry. 1993. Variable effects of endothelin-1 on $\left[\mathrm{Ca}^{2+}\right]_{i}$ transients, $\mathrm{pH}_{\mathrm{i}}$, and contraction in ventricular myocytes. Am. J. Physiol. 265:H793-H800.

19. Simonson, M., and M. J. Dunn. 1990. Endothelin-1 stimulates contraction of rat glomerular mesangial cells and potentiates $\beta$-adrenergic-mediated cyclic adenosine monophosphate accumulation. J. Clin. Invest. 85:790-797.

20. Bradford, M. M. 1976. A rapid and sensitive method for quantitation of microgram quantities of protein utilizing the principle of protein-dye binding. Anal. Biochem. 72:248-254.

21. Markewitz, B. A., J. R. Michael, and D. E. Kohan. 1993. Cytokine-induced expression of a nitric oxide synthase in rat renal tubule cells. J. Clin. Invest. 91:2138-2143.

22. Barnett, R. L., L. Ruffini, D. Hart, P. Mancuso, and E. P. Nord. 1994 Mechanism of endothelin activation of phospholipase $A_{2}$ in rat renal medullary interstitial cells. Am. J. Physiol. 266:F46-F56.

23. Miura, K., T. Yukimura, Y. Yamashita, T. Shimmen, M. Okumura, S. Yamanaka, M. Imanishi, and K. Yamamoto. 1991. Renal and femoral vascular responses to endothelin-1 in dogs: role of prostaglandins. J. Pharmacol. Exp. Ther. 256:11-17.

24. Boulanger, C. M., and T. F. Luscher. 1991. Hirudin and nitrates inhibit the thrombin-induced release of endothelin from the intact porcine aorta. Circ. Res. 68:1768-1772.

25. Madeddu, P., V. Anania, P. P. Parpaglia, C. Troffa, A. Pazzola, A. Soro, P. Manunta, G. Tonolo, M. P. Demontis, M. V. Varoni, et al. 1991. Endothelin1-induced renal vasoconstriction is blunted by enalaprilat and enhanced by EDRF antagonist in awake normotensive rats. Clin. Invest. Med. 14:600-606.

26. Wexler, A., R. Kalaba, and D. Marsh. 1991. Three-dimensional anatomy and renal concentrating mechanism. I. Modeling results. Am. J. Physiol. 260:F368-F383.

27. Han, J., K. Thompson, C.-L. Chou, and M. Knepper. 1992. Experimental tests of three-dimensional model of urinary concentrating mechanism. J. Am. Soc. Nephrol. 2:1677-1688.

28. Friedlaender, M. M., D. Jain, Z. Ahmed, D. Hart, R. L. Barnett, and E. P. Nord. 1993. Endothelin activation of phospholipase $\mathrm{D}$ : dual modulation by protein kinase $\mathrm{C}$ and $\mathrm{Ca}^{2+}$. Am. J. Physiol. 264:F845-F853.

29. Pupilli, C., M. Brunori, N. Misciglia, C. Selli, L. Ianni, M. Yanagisawa, M. Mannelli, and M. Serio. 1994. Presence and distribution of endothelin-1 gene expression in human kidney. Am. J. Physiol. 267:F679-F687.

30. Nadler, S. P., J. A. Zimplemann, and R. L. Hebert. 1992. Endothelin inhibits vasopressin-stimulated water permeability in rat terminal inner medullary collecting duct. J. Clin. Invest. 90:1458-1466.

31. Oishi, R., H. Nonoguchi, K. Tomita, and F. Marumo. 1991. Endothelin1 inhibits AVP-stimulated osmotic water permeability in rat medullary collecting duct. Am. J. Physiol. 261:F951-F956.

32. Zeidel, M. L., H. R. Brady, B. C. Kone, S. R. Gullans, and B. M. Brenner. 1989. Endothelin, a peptide inhibitor of $\mathrm{Na}^{+}-\mathrm{K}^{+}$-ATPase in intact tubular epithelial cells. Am. J. Physiol. 257:C1101-C1107.

33. Kohan, D. E., E. Padilla, and A. K. Hughes. 1993. Endothelin B receptor mediates ET-1 effects on cAMP and PGE2 accumulation in rat IMCD. Am. J. Physiol. 265:F670-F676. 